\title{
Perancangan Sistem Monitoring Power BTS (Base Transceiver Station) Menggunakan SMS Gateway Berbasis Mikrokontroler ATMega 8535
}

\author{
M. Aan Auliq ${ }^{1}$ \\ ${ }^{1,2}$ Jurusan Teknik Elektro, Universitas Muhammadiyah Jember, Indonesia
}

ABSTRACT

\begin{abstract}
Power system at BTS (Base Transceiver Station) plays an important role in supplying power to all devices that's supporting signal processing. But the power system needs its own surveillance, especially during the power outage, especially the electricity. The problems that are often experienced by the base stations, especially in areas of high levels of electrical outages. Based on this idea researcher design and create a monitoring tool power base stations using Atmega microcontroller-based SMS gateway 8535. This system aims to supervise / monitor the condition of the power system at BTS when disruptions, the system uses a voltage sensor as an indicator of disturbance and SHT11 sensor as a parameter measurement of temperature and humidity of the room. This is connected to the SMS Gateway using RS-232 communications and controlled using a microcontroller Atmega8535.
\end{abstract}

Keyword : BTS, SMS Gateway, Microcontroller

\begin{abstract}
ABSTRAK
Power system pada BTS (Base Transceiver Station) berperan penting dalam mensuplai tenaga terhadap seluruh perangkat-perangkat pendukung dalam pemrosesan sinyal. Akan tetapi power system perlu pengawasan tersendiri terutama saat terjadinya pemadaman listrik. Permasalahan ini sering dialami oleh BTS-BTS terutama di wilayah yang tingkat pemadaman listriknya tinggi. Hal inilah yang mendasari ide desain untuk membuat suatu alat monitoring power BTS menggunakan SMS gateway berbasis mikrokontroler Atmega 8535. Sistem ini bertujuan untuk mengawasi/memonitoring kondisi power system pada BTS ketika terjadinya gangguan, sistem ini menggunakan sensor tegangan sebagai indikator gangguan dan sensor SHT11 sebagai parameter pengukuran suhu dan kelembaban ruangan. Alat ini dikoneksikan terhadap SMS Gateway menggunakan komunikasi RS-232 dan dikontrol menggunakan Mikrokontroller Atmega8535.
\end{abstract}

Kata kunci : BTS, SMS Gateway, Mikrokontroller

\section{PENDAHULUAN}

Pemancar sinyal dikenal dengan BTS (Base Transceiver Station) yaitu perangkat yang menjembatani pengguna jaringan dengan jaringan lain. Dari beberapa BTS kemudian dikontrol oleh satu Base Station Controller (BSC) yang terhubung menggunakan sinyal radio. Setiap BTS membutuhkan catu daya agar dapat bekerja atau beroperasi. Setiap BTS untuk sumber listrik menggunakan supply dari PLN, Jika supply listrik dari PLN terhenti (padam) maka setiap pemancar menggunakan sumber listrik tambahan yaitu berupa baterai maupun genset [2].

Berdasarkan studi lapangan yang telah dilakukan penulis sebelumnya, yaitu disalah satu perusahaan yang bergerak dibidang telekomunikasi diperoleh kondisi dimana untuk proses monitoring telah menggunakan suatu alat guna untuk memonitor kondisi yang terjadi pada BTS. Alat tersebut merupakan produk jadi yang dibeli dari perusahaan China yaitu Huawei. Produk tersebut bekerja untuk memonitor kondisi BTS berbasis website yang telah terkoneksi oleh perusahaan pusat di Jakarta.

Penggunaan alat berbasis web memungkinkan adanya kelemahan karena proses monitoring hanya dapat dilakukan pada komputer yang telah teinstal aplikasi program monitoring Hal ini cukup mengganggu sebab para teknisi harus selalu terkoneksi dengan computer saat melakukan monitoring dan mengurangi fleksibilitas teknisi. Berdasarkan kelemahan tersebut maka dilakukan penelitian untuk membuat sebuah sistem yang dapat membantu teknisi dalam melakukan tugas pengawasan/monitoring secara realtime sehingga dapat mengetahui kondisi pada seluruh pemancar yang ada tanpa harus terkoneksi dengan computer. 
Tujuan dari penelitian ini yaitu merancang dan membuat Sistem berupa Alat Monitoring Power BTS Menggunakan SMS Gateway Berbasis Mikrokontroler Atmega 8535. Alasan system ini dipilih yaitu alat ini memiliki kelebihan dibanding alat yang sudah ada, yaitu informasi hasil monitoring dari alat ini berupa kondisi BTS yang terjadi dapat langsung tersampaikan kepada user sebagai teknisi melalui SMS Gateway. Sehingga user tidak harus membawa alat bantu computer. Permasalahan dalam penelitian ini dibatasi yaitu Alat ini merupakan prototype yang dikontrol menggunakan mikrokontroller Atmega 8535 yang diterapkan pada box dengan pendingin di dalamnya. Interfacing data menggunakan Modem Wavecom Fastrack M1306B, serta sensor suhu kelembaban menggunakan SHT. Alat ini digunakan untuk memonitor kondisi sumber listrik yang aktif berdasarkan nilai tegangan yang masuk. Sedangkan SMS Gateway digunakan saat adanya perubahan kondisi dari sumber listrik.

\section{METODE PENELITIAN}

Diagram blok proses kerja dari Sistem Monitoring Power BTS Menggunakan SMS Gateway Berbasis Mikrokontroler Atmega 8535, ditampilkan pada Gambar 1 dimana Mikrokontroler Atmega 8535 berfungsi sebagai penyimpan program, pengolah data, dan output data serta digunakan untuk system kendali [5]. Sensor SHT11 berfungsi untuk mengukur tingkat kelembaban dan suhu dalam ruangan. Sensor tegangan digunakan sebagai indikator kondisi dari sumber tenaga listrik yaitu PLN, genset, dan baterai, sedangkan untuk menampilkan output dari proses pengolahan data serta kondisi gangguan menggunakan LCD. Disamping itu digunakan pula IC Max 232 merupakan interface yang menghubungkan komunikasi antara mikrokontrol dengan modem wavecom yang digunakan sebagai pengirim informasi mengenai sistem kepada handphone server.

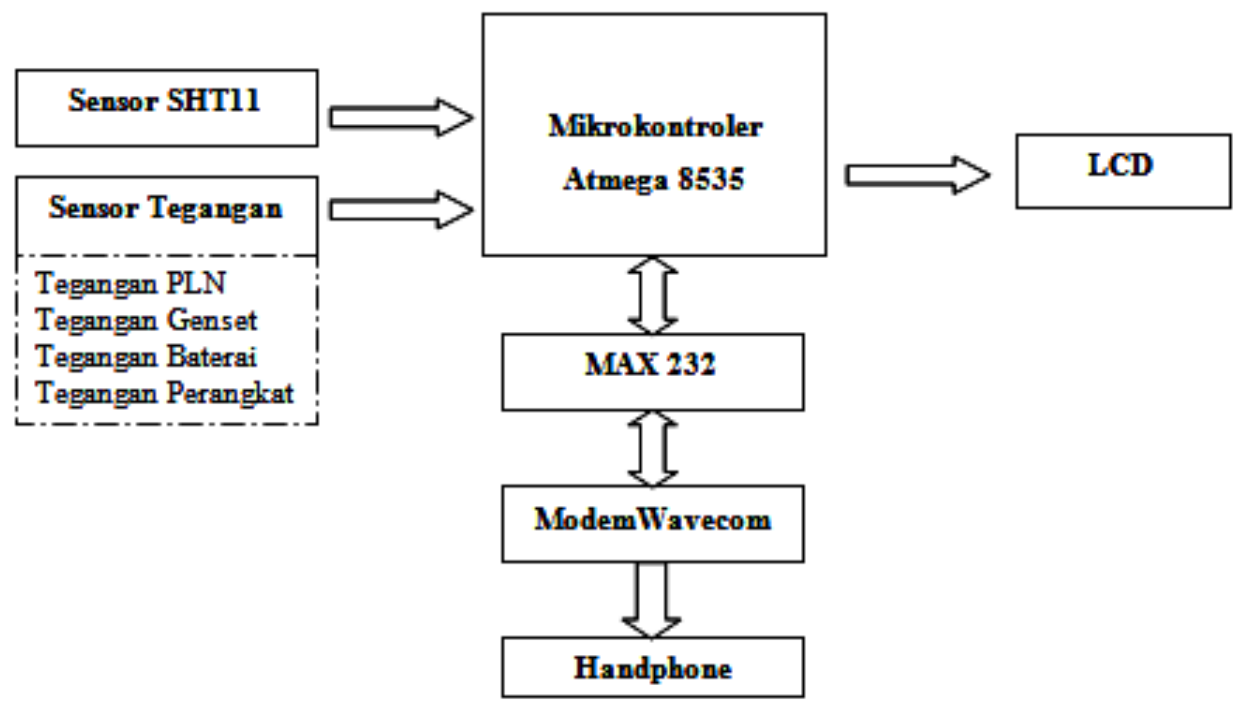

Gambar 1. Diagram Blok Sistem Kerja Alat

Perancangan perangkat keras menggunakan aplikasi Software Proteus sebagai alat bantu dalam proses desain rangkaian elektronika. Untuk hasil perancangan rangkaian keseluruhan system akan ditampilkan pada Gambar 2 berikut.

Adapun tahap perancangan hardware mekiputi :

1. Pembuatan Power Supply

2. Pembuatan minimum sistem Atmega 8535.

3. Perancangan sensor suhu SHT11.

4. Perancangan sensor tegangan.

5. Perancangan rangkaian interface komunikasi RS-232.

6. Perancangan LCD 2x16.

Perangkat lunak (software) memiliki fungsi utama sebagai penentu kehandalan dari sistem yang dibuat. Perangkat lunak diinputkan melalui sistem interface yang menghubungkan antara mikrokontrol dengan komputer yaitu downloader. Pemrograman yang digunakan pada proses pembuatan sistem ini 
menggunakan aplikasi Code Vision AVR dan menggunakan bahasa pemrograman bahasa C. Flowchart kendali system ditampilkan pada Gambar 3.

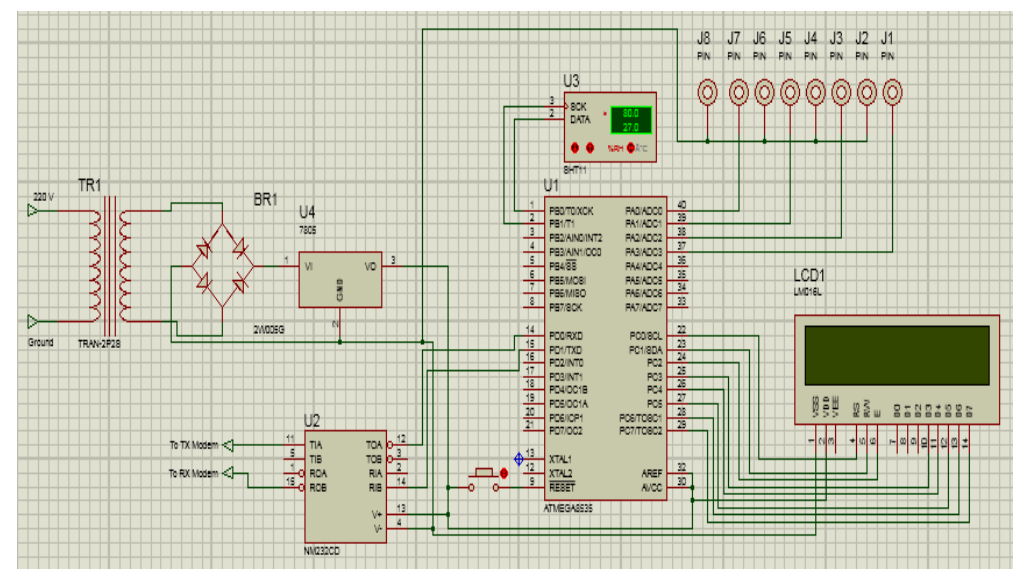

Gambar 2. Rangkaian Keseluruhan

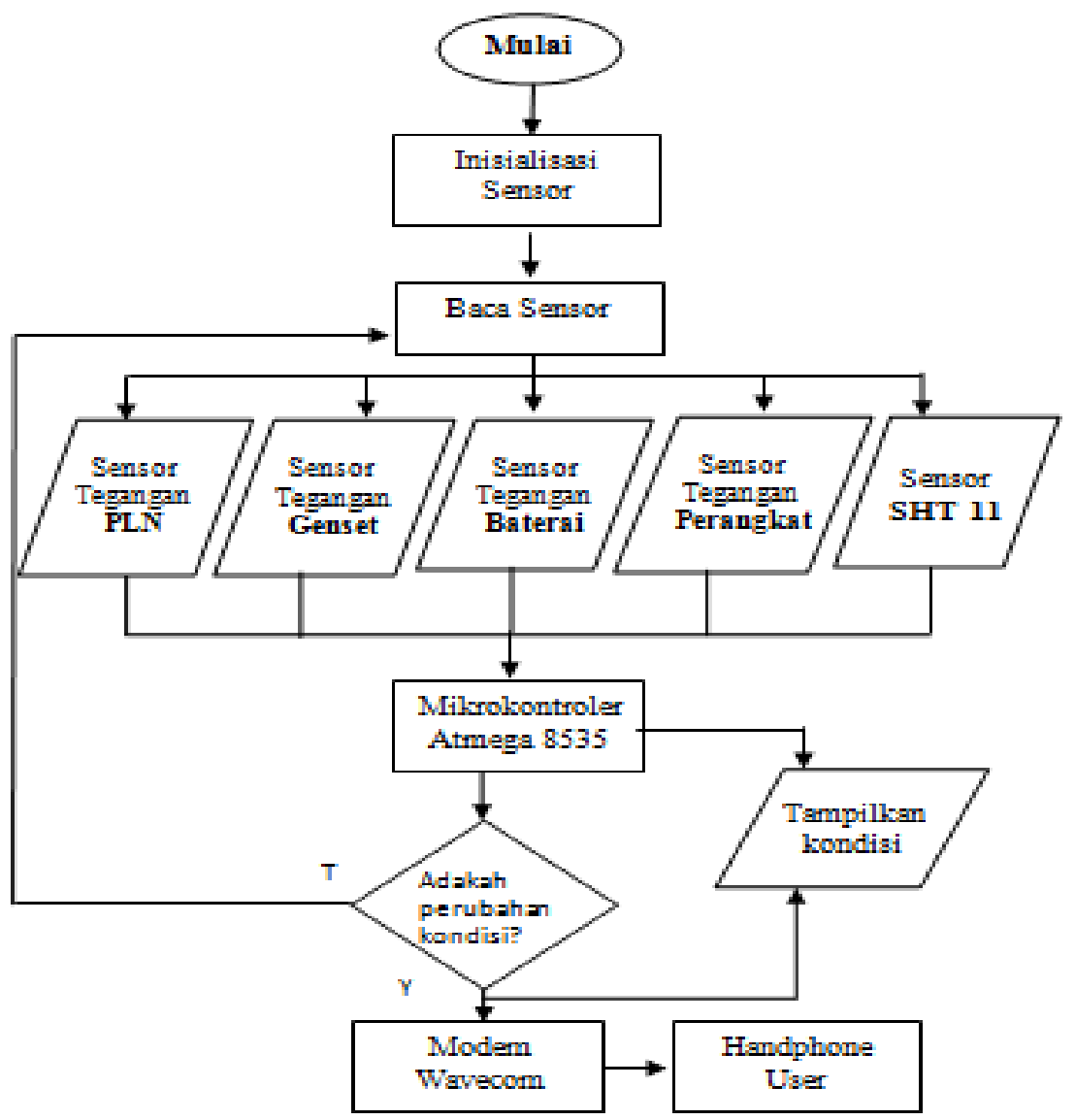

Gambar 3. Flowchart Kontroling Sistem

Alur kerja Flowchart Sistem Monitoring Power BTS Menggunakan SMS Gateway Berbasis Mikrokontroler Atmega 8535 yaitu pada saat awal, system melakukan inisialisasi pin masukan dan keluaran serta pembacaan data dari masing-masing sensor yang telah diset sebelumnya melalui pemograman. Selanjutnya data sensor diolah oleh mikrokontroller dan ditampilkan dalam LCD yang merupakan gambaran kondisi system BTS. Jika terjadi perubahan kondisi dari BTS maka mikrokontroller akan mengaktifkan modem wavecom untuk mengirimkan pesan via SMS pada user tentang perubahan kondisi BTS tersebut. 


\section{HASIL DAN PEMBAHASAN}

\subsection{Pengujian Sensor Tegangan}

Sensor tegangan merupakan bagian penting dalam sistem ini dimana sensor tegangan berfungsi untuk mengukur dan mengetahui kondisi tegangan sumber daya listrik yang dikeluarkan oleh PLN, genset, baterai dan supply pada perangkat pendukung BTS. Naik dan turunnya tegangan merupakan indikasi adanya perubahan kondisi BTS dan merupakan informasi yang harus diketahui oleh para teknisi agar dapat melakukan tindakan preventif terhadap sistem BTS. Hasil pengujian sensor tegangan akan ditampilkan dalam Tabel 1.

Tabel 1. Pengujian Sensor Tegangan

\begin{tabular}{llll}
\multirow{2}{*}{ Sumber } & Kondisi & $\begin{array}{l}\text { Tegangan Input } \\
(\mathbf{V})\end{array}$ & $\begin{array}{l}\text { Tegangan } \\
\text { output }(\mathbf{V})\end{array}$ \\
\hline \multirow{2}{*}{ Genset } & ON & 220 & 3,9 \\
\cline { 2 - 4 } & OFF & 0 & 0 \\
\hline \multirow{2}{*}{ Baterai } & ON & 220 & 3,9 \\
\hline \multirow{2}{*}{ Perangkat } & OFF & 0 & 0 \\
\cline { 2 - 5 } & OFF & 0 & 4,1 \\
\cline { 2 - 5 } & ON & 12 & 0 \\
\hline
\end{tabular}

\subsection{Pengujian Sensor SHT11}

Sensor SHT11 berfungsi sebagai alat pengukur perubahan suhu dan kelembaban udara pada ruangan perangkat BTS dengan nilai output berupa data digital yang sebelumnya telah terkalibrasi saat proses fabrikasi. Dalam penggunaan sensor suhu dan kelembaban pada alat memiliki range untuk suhu yaitu $5^{\circ} \mathrm{C}-$ $50^{\circ} \mathrm{C}$ dan untuk kelembaban yaitu 80\% - 95\%. Hasil pengujian sensor SHT11 ditampilkan pada Tabel 2.

Tabel 2 Pengujian Sensor SHT11

\begin{tabular}{|c|c|c|}
\hline Pengujian ke- & $\begin{array}{c}\text { Suhu } \\
\left({ }^{\circ} \mathbf{C}\right)\end{array}$ & Kelembaban (\% RH) \\
\hline \multirow{2}{*}{ 1. Suhu Kamar } & 28,9 & 55,6 \\
\hline & 29,5 & 60,8 \\
\hline \multirow{2}{*}{ 2. Suhu Box Non Pendingin } & 29,8 & 64,2 \\
\hline & 29,6 & 66,7 \\
\hline \multirow{2}{*}{$\begin{array}{l}\text { 3. Suhu Box dengan Pendingin (Lemari } \\
\text { Es) }\end{array}$} & 16,7 & 89,6 \\
\hline & 13,4 & 90,1 \\
\hline
\end{tabular}

\subsection{Pengujian LCD}

LCD berfungsi sebagai display untuk menampilkan informasi informasi tentang hasil pengukuran dari setiap sensor dalam system monitoring. Hasil pengujian LCD ditunjukan pada Tabel 3. berikut.

Tabel 3. Pengujian LCD

\begin{tabular}{ll}
\multicolumn{1}{c}{ Input (sensor tegangan) } & Karakter yang ditampilkan \\
\hline Sensor Tegangan PLN & V1: 222 V \\
\hline Sensor Tegangan Genset & V2: $222 \mathrm{~V}$ \\
\hline Sensor Tegangan Baterai & V3: $12 \mathrm{~V}$ \\
\hline Sensor Tegangan Perangkat & V4: $12 \mathrm{~V}$
\end{tabular}




\subsection{Pengujian Sistem Secara Keseluruhan}

Pengujian sistem secara keseluruhan akan dilakukan sebanyak 10 kali percobaan untuk menentukan ketahanan sistem, hasil pengujian sistem secara keseluruhan dapat dilihat pada Tabel 4 berikut

Tabel 4. Pengujian Sistem Secara Keseluruhan (Dalam Sehari)

\begin{tabular}{rlll}
\multicolumn{1}{l}{$\begin{array}{l}\text { Perc. } \\
\text { ke- }\end{array}$} & Kondisi & $\begin{array}{l}\text { Hasil Tampilan } \\
\text { LCD }\end{array}$ & $\begin{array}{l}\text { Hasil SMS } \\
\text { Gateway }\end{array}$ \\
\hline 1. & PLN ON & $\begin{array}{l}\text { Berhasil } \\
\text { menampilkan }\end{array}$ & $\begin{array}{l}\text { Berhasil } \\
\text { mengirim }\end{array}$ \\
\hline 2. & Genset ON & $\begin{array}{l}\text { Berhasil } \\
\text { menampilkan }\end{array}$ & $\begin{array}{l}\text { Berhasil } \\
\text { mengirim }\end{array}$ \\
\hline 3. & Baterai ON & $\begin{array}{l}\text { Berhasil } \\
\text { menampilkan }\end{array}$ & $\begin{array}{l}\text { Berhasil } \\
\text { mengirim }\end{array}$ \\
\hline 4. & Semua OFF & $\begin{array}{l}\text { Berhasil } \\
\text { menampilkan }\end{array}$ & $\begin{array}{l}\text { Berhasil } \\
\text { mengirim }\end{array}$ \\
\hline 5. & $\begin{array}{l}\text { PLN ON, } \\
\text { Perangkat OFF }\end{array}$ & $\begin{array}{l}\text { Berhasil } \\
\text { menampilkan }\end{array}$ & $\begin{array}{l}\text { Berhasil } \\
\text { mengirim }\end{array}$ \\
\hline 6. & PLN ON & $\begin{array}{l}\text { Berhasil } \\
\text { menampilkan }\end{array}$ & $\begin{array}{l}\text { Berhasil } \\
\text { mengirim }\end{array}$ \\
\hline 7. & Genset ON & $\begin{array}{l}\text { Berhasil } \\
\text { menampilkan }\end{array}$ & $\begin{array}{l}\text { Berhasil } \\
\text { mengirim }\end{array}$ \\
\hline 8. & Baterai ON & $\begin{array}{l}\text { Berhasil } \\
\text { menampilkan }\end{array}$ & $\begin{array}{l}\text { Berhasil } \\
\text { mengirim }\end{array}$ \\
\hline 9. & Semua OFF & $\begin{array}{l}\text { Berhasil } \\
\text { menampilkan }\end{array}$ & $\begin{array}{l}\text { Berhasil } \\
\text { mengirim }\end{array}$ \\
\hline 10. & $\begin{array}{l}\text { Genset ON, } \\
\text { Perangkat OFF }\end{array}$ & $\begin{array}{l}\text { Berhasil } \\
\text { menampilkan }\end{array}$ & $\begin{array}{l}\text { Berhasil } \\
\text { mengirim }\end{array}$ \\
\hline
\end{tabular}

Pada tabel 4 diperoleh data berupa hasil pengujian sistem, dimana display LCD menunjukkan keberhasilan pengiriman SMS terhadap user yang didalamnya terdapat informasi dan data mengenai kondisi sumber tenaga listrik yang aktif maupun nilai tegangan listrik yang terukur oleh alat serta nilai dari pengukuran suhu dan kelembaban udara. Berikut merupakan display LCD hasil desain alat saat pengujian yang ditampilkan pada Gambar 4.
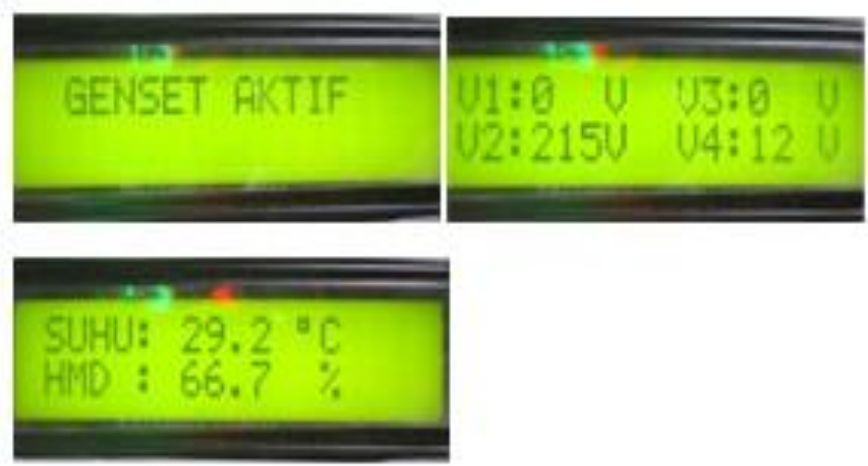

Gambar 4 Tampilan LCD Hasil Pengujian Alat

\subsection{Pengujian Keandalan Sistem}

Pengujian keandalan sistem akan dilakukan dalam waktu 2 (dua) hari dengan pembagian 3 periode waktu yaitu pagi, siang, dan malam dimana sistem akan ditempatkan pada system BTS. Hasil pengujian keandalan sistem ditampilkan pada Tabel 5. 
Tabel 5 Pengujian Keandalan Sistem

\begin{tabular}{|c|c|c|c|}
\hline $\begin{array}{l}\text { Hari } \\
\text { ke. }\end{array}$ & $\begin{array}{c}\text { Tanggal } \\
\text { / Jam }\end{array}$ & Hasil & $\begin{array}{l}\text { Time } \\
\text { Delay } \\
\text { SMS } \\
\quad \text { (detik) }\end{array}$ \\
\hline \multirow[t]{3}{*}{1.} & $\begin{array}{l}03-02-17 \\
/ 08.00\end{array}$ & $\begin{array}{l}\text { Berhasil menampilkan } \\
\text { dan mengirim }\end{array}$ & 14 \\
\hline & $\begin{array}{l}03-02-17 \\
/ 13.00\end{array}$ & $\begin{array}{l}\text { Berhasil menampilkan } \\
\text { dan mengirim }\end{array}$ & 13 \\
\hline & $\begin{array}{l}03-02-17 \\
/ 20.00\end{array}$ & $\begin{array}{l}\text { Berhasil menampilkan } \\
\text { dan mengirim }\end{array}$ & 14 \\
\hline \multirow[t]{3}{*}{2.} & $\begin{array}{l}04-02-17 \\
/ 08.00\end{array}$ & $\begin{array}{l}\text { Berhasil menampilkan } \\
\text { dan mengirim }\end{array}$ & 14 \\
\hline & $\begin{array}{l}04-02-17 \\
/ 13.00\end{array}$ & $\begin{array}{l}\text { Berhasil menampilkan } \\
\text { dan mengirim }\end{array}$ & 14 \\
\hline & $\begin{array}{l}04-02-17 \\
/ 20.00\end{array}$ & $\begin{array}{l}\text { Berhasil menampilkan } \\
\text { dan mengirim }\end{array}$ & 13 \\
\hline \multicolumn{2}{|c|}{$\begin{array}{l}\text { Total } \\
\text { keberhasilan }\end{array}$} & 6 & \\
\hline \multicolumn{2}{|c|}{ Total kegagalan } & $\mathbf{0}$ & \\
\hline $\begin{array}{l}\% \\
\text { siste }\end{array}$ & la & 100 & \\
\hline
\end{tabular}

Perhitungan hasil pengujian berdasarkan lama waktu tunda (delay) dalam proses pengiriman SMS ditampilkan pada Tabel 6 berikut

Tabel 6 Perhitungan Time Delay SMS.

\begin{tabular}{lll}
\multicolumn{1}{c}{ Percobaan ke- } & Time delay $(\mathbf{T d})$ & $|\mathbf{T t}|=(\mathbf{T d}-\overline{\mathbf{T d}})$ \\
\hline 1 & 14 detik & 0,3 detik \\
\hline 2 & 13 detik & 0,7 detik \\
\hline 3 & 14 detik & 0,3 detik \\
\hline 4 & 14 detik & 0,3 detik \\
\hline 5 & 14 detik & 0,3 detik \\
\hline 6 & 13 detik & 0,7 detik \\
\hline Jumlah & 82 detik & 2,6 detik \\
Rata-rata Time & 13,7 detik \\
delay $(\overline{T d})$ &
\end{tabular}

Sesuai dari data yang diperoleh dalam proses pengiriman SMS terdapat time delay atau waktu tunda penerimaan data pada user. Hal itu disebabkan oleh proses komunikasi yang terjadi pada operator yang digunakan [4]. Time delay (Td) dalam proses pengiriman berkisar pada rentang waktu 13 sampai 15 detik, sehingga dengan rentang waktu tersebut dan dalam 6 kali percobaan dapat diambil rata-rata dari time delay sebesar 13,7 detik.

Indikator keberhasilan alat ini ditentukan oleh proses pembacaan supply yang aktif dan juga pembacaan terhadap sensor suhu dan kelembaban yang nantinya ditampilkan pada layar LCD maupun dalam pengiriman SMS terhadap user.

\section{KESIMPULAN}

Telah berhasil dilakukan perancangan dan pembuatan Sistem Monitoring Power BTS Menggunakan SMS Gateway Berbasis Mikrokontroler Atmega 8535. Dari data analisa dan pengujian alat diketahui bahwa sistem ini memiliki keandalan sistem hingga $100 \%$ dan memiliki rentang waktu tunda (delay) yang relative singkat yaitu sebesar 13,7 detik dengan waktu pengujian selama 2 hari dan dalam 3 periode waktu, serta sistem dapat dioperasikan pada ruangan berpendingin dengan suhu ruangan $5^{\circ} \mathrm{C}-50^{\circ} \mathrm{C}$ dengan kelembaban udara mencapai $80 \%$ - 95\% pada ruang kabinet tertutup 


\section{REFERENSI}

[1] A.B. Nugroho, "Pembuatan Prototype Robot Beroda berbasis mikrokontroller dan Sensor Easy Voice Recognition Sebagai Alat Bantu Penderita Disabilitas”, Jurusan Teknik Elektro Universitas Muhammadiyah Jember, 2016

[2] Mandarani, Putri. "Perancangan dan Implementasi User Interface Berbasis Web Untuk Monitoring

Suhu, Kelembaban dan Asap Pada Ruangan Berbeda Dengan Memanfaatkan Jaringan Local Area Network”, Fakultas Teknologi Industri Institut Teknologi Padang, 2014

[3] Nugroho, Tunggul Arief, "Remote Monitoring Berbasis GPRS (Studi Kasus : Monitoring Shelter Bts)”, Jurusan Teknik Elektro, Institut Teknologi Harapan Bangsa, 2010

[4] Petruzella, Frank D, “ Elektronik Industri”. Yogyakarta, 1996

[5] Wadhana, Lingga “ Mikrokontroller AVR Seri ATMega 8535 Simulasi Hardware dan Aplikasi, Andi Yogyakarta, 2006 


\section{RIWAYAT HIDUP PENULIS}

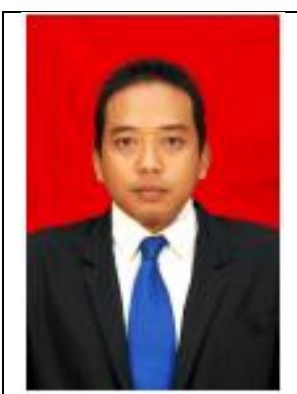

M. Aan Auliq adalah dosen tetap di lingkungan Program Studi Teknik Elektro Universitas Muhammadiyah Jember. Menyelesaikan pendidikan S2 dari Universitas Brawijaya pada bidang Teknik Tenaga Listrik, saat ini Aan menjabat sebagai Wakil Dekan Fakultas Teknik. Bidang penelitian yang digelutinya adalah arus kuat. 